\title{
Concretos refratários engenheirados com expansão controlada para panelas de siderurgia
}

\section{(Engineered refractory castables with controlled expansion for molten steel ladles)}

\author{
M. A. L. Braulio' , D. H. Milanez ${ }^{1}$, E. Y. Sako , M. A. M. Brito ${ }^{2}$ L. R. M. Bittencourt ${ }^{2}$, V. C. Pandolfelli ${ }^{1}$ \\ ${ }^{1}$ Grupo de Engenharia de Microestrutura de Materiais - GEMM \\ Departamento de Engenharia de Materiais, Universidade Federal de S. Carlos \\ Rod. Washington Luiz, km 235, C.P. 676, S. Carlos, SP 13565-905 \\ ${ }^{2}$ Magnesita S.A., Centro de Pesquisas e Desenvolvimento - CPqD \\ Praça Louis Ensch, 240, Contagem, MG \\ vicpando@power.ufscar.br
}

\begin{abstract}
Resumo
A seleção de revestimentos refratários para a siderurgia é dependente de fatores termodinâmicos e microestruturais. O emprego de óxidos termodinamicamente estáveis, como a alumina e a magnésia, é fundamental para o aumento de vida útil do produto, por meio da melhoria na resistência à corrosão. Em temperaturas elevadas, estes óxidos reagem entre si, resultando na formação de espinélio, um composto quimicamente adequado para o contato com escórias agressivas. Apesar desta vantagem, um extenso controle da espinelização in-situ é necessário, uma vez que esta reação possui caráter expansivo, podendo danificar a integridade estrutural do material. Deste modo, o objetivo deste trabalho é a análise do efeito das matérias-primas que constituem a matriz de concretos espinelizados sob a expansão residual resultante. Por meio deste estudo, concretos com microestruturas engenheiradas podem ser projetados, associando benefícios como elevada resistência à corrosão, devido à presença de espinélio, e tenacificação do sistema, decorrente de um estado de compressão gerado no revestimento da panela relacionado à expansão obtida em um espaço constrito. Sendo assim, concretos refratários adequados para esta aplicação podem ser produzidos, possibilitando vantagens econômicas associadas a um superior desempenho do revestimento refratário.
\end{abstract}

Palavras-chave: concreto refratário, espinélio, expansão.

Abstract

Thermodynamics and microstructural analysis are of utmost importance to choose the best refractory lining for molten steel containers. In order to extend ladle lining life, thermodynamically stable oxides, such as alumina and magnesia, are essential. At higher temperatures, the in-situ reaction between these two oxides leads to the formation of spinel, which has an outstanding corrosion resistance. Due to this reaction, alumina-magnesia castables are liable to a great volume expansion. Because of this, controlling the spinel formation is fundamental to keep the integrity of the material. The extent to which this reaction affects the properties of these castables depends on the matrix raw materials. Considering this aspect, the aim of this study is to design a residual expansion based on previously engineered microstructure. Consequently, the association of chemical resistance and an excellent toughening mechanism can be attained, resulting in materials with better performance.

Keywords: refractory castables, spinel, expansion.

\section{INTRODUÇÃO}

Os revestimentos refratários das panelas de siderurgia estão expostos ao ambiente severo do processo de refinaria secundária, que envolve elevadas temperaturas, escórias agressivas e elevados tempos de residência [1]. Neste contexto, destacam-se os concretos do sistema aluminamagnésia, as quais apresentam uma característica particular que é a formação de espinélio in-situ em temperaturas superiores a $1000{ }^{\circ} \mathrm{C}$. O espinélio $\left(\mathrm{MgAl}_{2} \mathrm{O}_{4}\right)$ possui uma excelente combinação de propriedades, como elevada refratariedade, resistência mecânica e resistência à corrosão.

No entanto, a formação de espinélio na matriz do concreto é acompanhada por uma expansão volumétrica, podendo comprometer estruturalmente o material. O efeito final da expansão volumétrica é dependente das matérias-primas da matriz deste concreto, composta por aluminas reativas, microssílica, magnésia e agentes ligantes. Parâmetros como tamanho de grão, área superficial, pureza e teor adicionado apresentam um forte efeito no comportamento de expansão deste material.

Considerando-se tais aspectos, o objetivo principal deste 
trabalho é garantir uma espinelização in-situ controlada durante a sinterização, por meio da engenharia de microestrutura do concreto. Deste modo, pode-se aproveitar as vantagens decorrentes da espinelização, contribuindo para a melhoria do desempenho e eficiência destes materiais quando aplicados na indústria siderúrgica.

\section{Produção de concretos espinelizados}

Os concretos refratários são usualmente constituídos de agregados, partículas finas (matriz), agentes ligantes e aditivos químicos. Para estes materiais, existem duas rotas distintas para a incorporação do espinélio. A primeira abordagem consiste na adição de espinélios pré-formados, como agregados ou na matriz do concreto. A segunda técnica é a de obtenção da espinelização in-situ, onde a magnésia e a alumina são acrescentadas à matriz e o espinélio é formado em temperaturas entre 1000 e $1500{ }^{\circ} \mathrm{C}$ [2].

As principais vantagens do uso de espinélios pré-formados se relacionam à presença desta fase em temperaturas inferiores às de sua obtenção e à ausência de expansão decorrente da sua formação in-situ. No entanto, o processo de pré-espinelização apresenta um consumo considerável de energia, o que resulta em elevado custo, além de seu desempenho termomecânico não ser tão eficiente quanto aquele gerado in-situ. $\mathrm{Na}$ espinelização in-situ, as dificuldades encontradas se referem justamente aos problemas de expansão, sejam eles decorrentes da hidratação da magnésia ou mesmo da reação de espinelização. A vantagem é a geração de um espinélio finamente disperso por toda a matriz do concreto aumentando a resistência à penetração de escórias. Adicionalmente, a expansão proveniente da formação de espinélio propicia a tenacificação e densificação do material, melhorando o desempenho do material.

Com relação aos componentes da matriz (partículas finas) de concretos espinelizados in-situ são usualmente empregadas aluminas reativas, magnésias e microssílica. Nestes sistemas, os agentes ligantes mais importantes são os cimentos de aluminato de cálcio. Estas matérias-primas influenciam significativamente na reação de espinelização, alterando o resultado residual de expansão volumétrica.

\section{Concretos refratários espinelizados in-situ}

A espinelização in-situ é um fenômeno dependente da temperatura e do teor de magnésia presente. A temperatura inicial de formação do $\mathrm{MgAl}_{2} \mathrm{O}_{4}$, usando-se partículas precursoras micrométricas, é de aproximadamente $1000{ }^{\circ} \mathrm{C}$ e sua geração aumenta significativamente com a elevação da temperatura para $1200-1400{ }^{\circ} \mathrm{C}$. O teor de magnésia também influencia no comportamento de expansão térmica deste tipo de concreto: quanto maior a quantidade de $\mathrm{MgO}$ presente, maior o teor de espinélio formado, o que resulta normalmente em maior expansão linear permanente, como mostra a Fig. 1 [3].

Outra questão importante se relaciona ao efeito do tamanho de grão da magnésia na espinelização: quanto

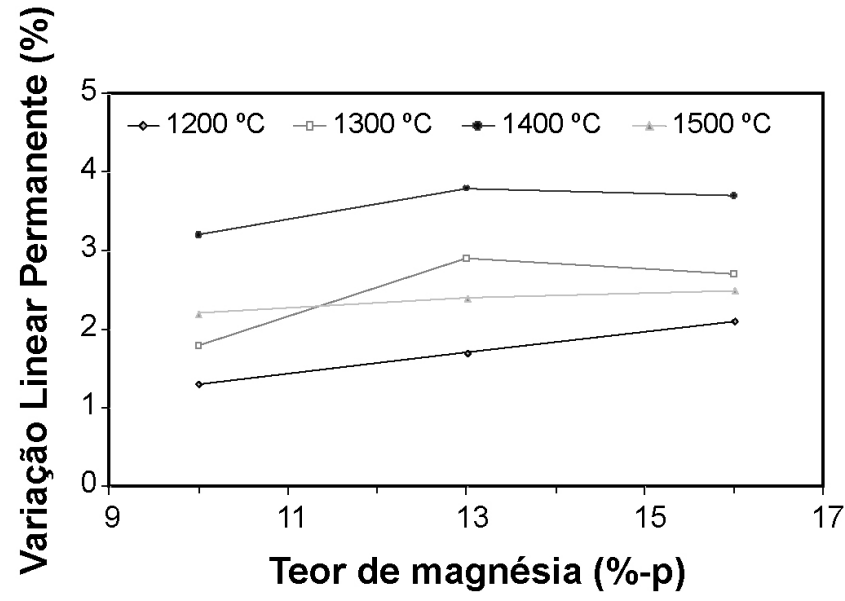

Figura 1: Efeito do teor de magnésia na variação linear dimensional [3]. [Figure 1: Magnesia content effect on the permanent linear change [3].]

maior o tamanho do $\mathrm{MgO}$ utilizado, maior é a variação linear permanente (Fig. 2) e maior a porosidade aparente do sistema [3]. Este fato é atribuído aos distintos coeficientes de expansão térmica da magnésia e da alumina e também à distribuição não uniforme do espinélio no concreto.

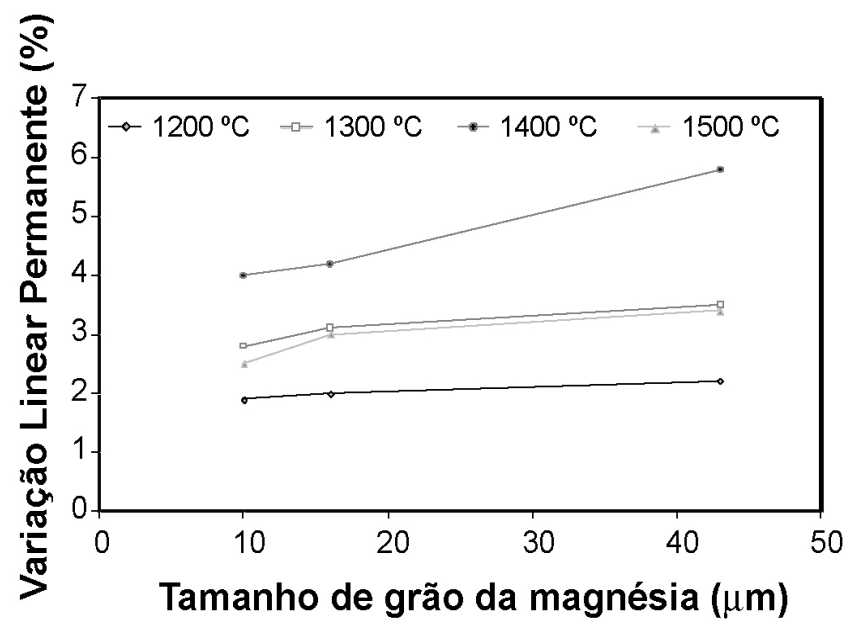

Figura 2: Efeito do tamanho de grão da magnésia na variação linear dimensional [3].

[Figure 2: Magnesia grain size effect on the permanent linear change [3].]

Adicionalmente, a pureza química e os outros componentes que constituem os grãos de $\mathrm{MgO}$ (como o $\mathrm{CaO}$ e a $\mathrm{SiO}_{2}$ ) também interferem na formação de espinélio. Conforme observado por Soudier, a utilização de uma magnésia de elevada área superficial implica em uma maior hidratação e aumento da atividade química da magnésia, resultando em uma formação mais rápida de espinélio. A Tabela I apresenta o efeito da maior formação de brucita em magnésias mais puras e com maior razão $\mathrm{CaO} / \mathrm{SiO}_{2}$ [4].

Deste modo, parece coerente que o uso de magnésias mais grosseiras pode solucionar os problemas decorrentes de uma hidratação excessiva, já que esta é um fenômeno superficial. 
Tabela I - Resultados da hidratação de distintas fontes de magnésia após o ensaio de autoclave [4].

[Table I - Hydration results after autoclave tests for distinct magnesia types [4].]

\begin{tabular}{|c|c|c|c|}
\hline Tipos & $\mathrm{MgO}-1$ & $\mathrm{MgO}-2$ & $\mathrm{MgO}-3$ \\
\hline \multicolumn{4}{|c|}{ Análise química } \\
\hline $\mathrm{CaO} / \mathrm{SiO}_{2}$ & 3,75 & 1,35 & 1,09 \\
\hline $\mathrm{MgO}(\%-p)$ & 98,7 & 95,8 & 93,4 \\
\hline \multicolumn{4}{|c|}{ Teor de $\mathrm{MgO}$ transformado em $\mathrm{Mg}(\mathrm{OH})_{2}$ - [\%-p] } \\
\hline & 16 & 4 & 0,2 \\
\hline
\end{tabular}

No entanto, é importante ressaltar que esta opção pode reduzir a quantidade de espinélio formado, além de poder gerar resultados deletérios, como uma maior expansão volumétrica ou micro-trincamento excessivo do concreto devido ao elevado coeficiente de expansão térmica da magnésia [4].

Outro aspecto que contribui para a expansão do sistema alumina-magnésia é a presença de cimentos de aluminato de cálcio. Além da espinelização, uma fase adicional que ocorre em alta temperatura é o $\mathrm{CaO}-6 \mathrm{Al}_{2} \mathrm{O}_{3}\left(\mathrm{CA}_{6}\right)$, devido a reação entre a alumina e a cálcia. Experimentalmente, verificouse em concretos espinelizados in-situ que os cristais de $\mathrm{CA}_{6}$ formados penetram no interior dos grãos de aluminas tabulares. Em concretos aluminosos (sem espinélio), também são encontrados cristais de $\mathrm{CA}_{6}$, porém estes são menos interligados aos grãos e maiores em tamanho. Condições de processamento, como a temperatura de cura do concreto, influenciam no tamanho de cristal formado e nas propriedades físicas do produto [5].

Em concretos alumina-magnésia, os cristais de $\mathrm{CA}_{6}$ se formam tanto ao redor dos grãos como na matriz do concreto em temperaturas superiores a $1400{ }^{\circ} \mathrm{C}$. Adicionalmente, o $\mathrm{CA}_{6}$ pode ser encontrado no interior dos poros dos grãos de aluminas, devido a um rápido processo de difusão pelos contornos de grãos ou por um processo de transporte por vapor [5]. Com a elevação da temperatura para $1500{ }^{\circ} \mathrm{C}$, os cristais de $\mathrm{CA}_{6}$ são responsáveis por um mecanismo de ruptura dos grãos de alumina tabular (Fig. 3), causada por uma extensiva penetração no interior dos grãos de alumina.

Embora a formação de $\mathrm{CA}_{6}$ possibilite a melhoria de algumas propriedades, como a resistência à corrosão e a resistência ao choque térmico, sua obtenção deve ser controlada, uma vez que pode gerar um trincamento excessivo, resultando na redução da resistência à penetração por escória e da resistência mecânica. Neste sentido, o controle do teor de cimento da composição torna-se uma variável importante para a otimização das formulações.

Outra matéria-prima que interfere nas propriedades de concretos alumina-magnésia é a microssílica, adicionada com a finalidade de gerar uma pequena quantidade de fase líquida para acomodar a formação de espinélio [6]. Apesar de ser utilizada em pequenas quantidades (normalmente, menos

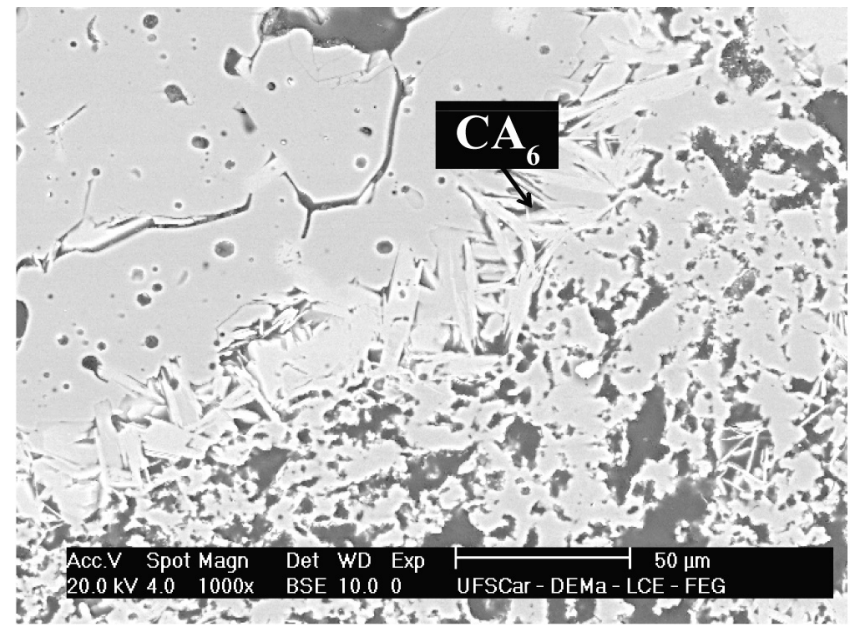

Figura 3: Agulhas de $\mathrm{CA}_{6}$ em um concreto alumina-magnésia queimado a $1500^{\circ} \mathrm{C}$.

[Figure 3: $C A_{6}$ needles in an alumina-magnesia castable fired at $1500{ }^{\circ} \mathrm{C}$.]

do que $1 \%$-p), é grande o seu efeito nas propriedades dos concretos, especialmente na fluência, já que em temperaturas elevadas, fases de baixa refratariedade no sistema $\mathrm{CaO}$ $\mathrm{MgO}-\mathrm{Al}_{2} \mathrm{O}_{3}-\mathrm{SiO}_{2}$ (CMAS) são formadas. A razão $\mathrm{CaO} / \mathrm{SiO}_{2}$ é um fator importante na determinação do teor e viscosidade do líquido formado, bem como na resistência mecânica a quente e resistência à fluência dos concretos refratários. $\mathrm{O}$ sistema ternário $\mathrm{Al}_{2} \mathrm{O}_{3}-\mathrm{MgO}-\mathrm{CaO}$, por outro lado, apresenta elevada refratariedade, devido às altas temperaturas dos pontos invariantes do diagrama [7].

A formação de fase líquida colabora também para a aceleração das reações de espinelização e formação de $\mathrm{CA}_{6}$. Observações experimentais em concretos alumina-magnésia ligados por cimento, por exemplo, indicam o crescimento de cristais aciculares de $\mathrm{CA}_{6}$ apenas em composições contendo microssílica $(0,75 \%$-p) contribuindo para a evolução das reações em altas temperaturas [8].

Sendo assim, diante da grande quantidade de variáveis que interferem na espinelização, a análise do efeito das matérias primas é de fundamental importância para se projetar a microestrutura desejada e se atingir as propriedades adequadas. Embora a literatura tenha abordado alguns aspectos relacionados à expansão, não é conhecida a origem dos concretos produzidos e seu processamento, o que dificulta a conclusão sobre a influência das matérias-primas na expansão. Deste modo, o presente trabalho visa isolar as variáveis microestruturais, para se atingir uma expansão engenheirada e controlada, contribuindo para o aumento de vida útil deste tipo de concreto e aumento de produtividade do setor siderúrgico.

\section{MATERIAIS E MÉTODOS}

Neste trabalho, foram utilizados como agregados aluminas tabulares da Almatis-EUA, nas frações granulométricas na faixa de 6 a $0,2 \mathrm{~mm}$. 
A matriz dos concretos foi projetada com o uso de sínteres de magnésia (Magnesita S.A., Brasil), alumina reativa CL370 $\left(\mathrm{D}_{50}=2,9 \mu \mathrm{m}\right.$, Almatis, EUA) e microssílica $971 \mathrm{U}\left(\mathrm{D}_{50}=0,2 \mu \mathrm{m}\right.$, Elkem Materials, Noruega). Com relação aos sínteres de magnésia, foram escolhidos tamanhos granulométricos distintos $(<45 \mu \mathrm{m} \mathrm{e}<100 \mu \mathrm{m})$ e diferentes purezas (95\%-p e 98\%-p de $\mathrm{MgO}$ ). O ligante escolhido foi o cimento de aluminato de cálcio Secar 71 (Kerneos, França). Um policarboxiliato foi empregado como dispersante.

Foram projetadas formulações com coeficientes de empacotamento de partículas igual a 0,26 e 0,31 utilizandose o modelo de Alfred [9]. Para auxiliar no projeto das formulações foi utilizado um software desenvolvido em parceria entre o grupo de pesquisa GEMM/DEMa/UFSCar e a Alcoa Alumínio S.A.. Os concretos foram elaborados com teores de água que garantem uma fluidez mínima inicial sobre vibração de $80 \%$, garantindo-se uma moldagem adequada.

Para análise da espinelização in-situ foram utilizados os seguintes ensaios: flexão em três pontos para avaliação da resistência mecânica residual e medida da variação linear dimensional após queimas por cinco horas nas temperaturas de 1150,1300 e $1500{ }^{\circ} \mathrm{C}$. Adicionalmente, foi utilizado o ensaio de expansão térmica em um equipamento Netzsch RUL 421E.

A análise das propriedades mecânicas por meio do ensaio de flexão 3 pontos (MTS Systems Corp., modelo 810, EUA) foi realizada em corpos de prova na forma de barras $(25 \mathrm{~mm}$ x $25 \mathrm{~mm}$ x $150 \mathrm{~mm}$ ). A taxa de aplicação de carga foi de 24,9 $\mathrm{N} / \mathrm{s}$ e o módulo de ruptura foi obtido por:

$$
\sigma_{\mathrm{R}}=\frac{3}{2} \cdot\left(\frac{\mathrm{P}_{\text {max }} \cdot \mathrm{L}}{\mathrm{b} \cdot \mathrm{h}^{2}}\right)
$$

onde, $\mathrm{P}_{\text {máx }}$ é a força de ruptura $(\mathrm{N})$, b é a largura do corpo de prova $(\mathrm{mm})$, h é a altura do corpo de prova $(\mathrm{mm})$ e L é a distância entre os dois apoios (mm).

A medida da variação linear dimensional (VLD) residual do material também foi efetuada em amostras na forma de barras ( $25 \mathrm{~mm} \times 25 \mathrm{~mm} \times 150 \mathrm{~mm})$. O cálculo da VLD é obtido por meio da medida do comprimento inicial da barra (antes da sinterização) - $\mathrm{L}_{\mathrm{i}}$ - e do comprimento final da amostra (após sinterização) - $\mathrm{L}_{\mathrm{f}}$ :

$$
\operatorname{VLD}(\%)=\frac{\mathrm{L}_{\mathrm{f}}-\mathrm{L}_{\mathrm{i}}}{\mathrm{L}_{\mathrm{i}}} \cdot 100
$$

O acompanhamento da espinelização in-situ foi realizado pela análise da variação linear observada no ensaio expansão térmica, utilizando-se o resultado gerado pelo equipamento modelo RUL 421E, da Netzsch. Foram preparadas amostras cilíndricas $(\mathrm{h}=\mathrm{d}=50 \mathrm{~mm})$ com um furo central de 12,4 $\mathrm{mm}$. O ensaio foi efetuado a uma taxa de $3{ }^{\circ} \mathrm{C} / \mathrm{min}$ até a temperatura de $1500{ }^{\circ} \mathrm{C}$, sob carga compressiva de 0,02 $\mathrm{MPa}$. As amostras permaneceram nesta temperatura por um intervalo de $5 \mathrm{~h}$. Os testes foram realizados em amostras verdes (pré-calcinadas a $600{ }^{\circ} \mathrm{C}$ por $5 \mathrm{~h}$ ), visando-se o estudo da formação de espinélio in-situ e sinterização do material.

\section{RESULTADOS E DISCUSSÃO}

O primeiro aspecto avaliado no concreto aluminamagnésia foi a variação do teor de cimento. Para tal, foram projetadas composições contendo 2,4 e $6 \%$-p deste material. Conforme a Fig. 4 é evidente a contribuição da presença de cimento na expansão resultante. A maior expansão para o concreto com maior teor de cimento é atribuída à formação de $\mathrm{CA}_{6}$. Como pode ser avaliada na Fig. 5, a taxa de variação dimensional aumenta significativamente em aproximadamente $1200{ }^{\circ} \mathrm{C}$, associado ao fenômeno de espinelização. Já em $1500{ }^{\circ} \mathrm{C}$, percebe-se uma maior taxa de variação linear com o aumento do teor de cimento,

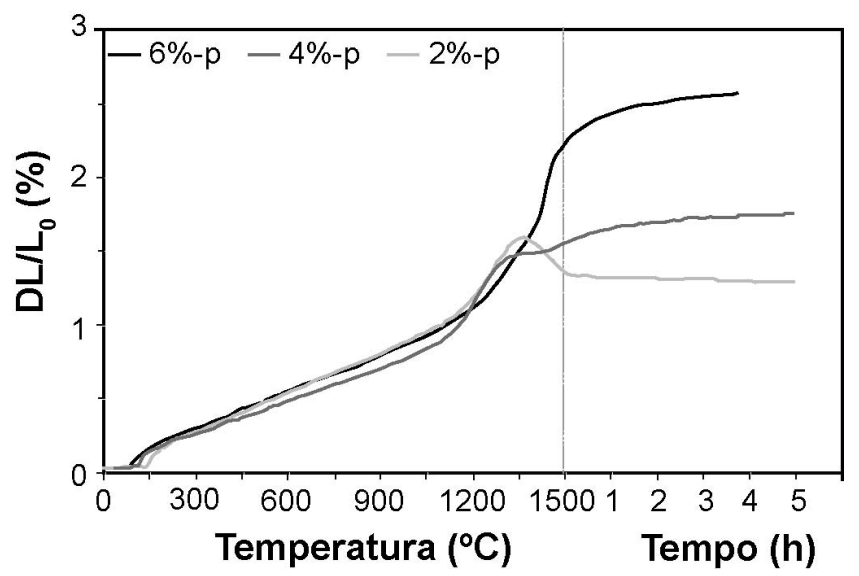

Figura 4: Expansão térmica de concretos com teores de cimento distintos.

[Figure 4: Thermal expansion of castables with distinct cement content.]

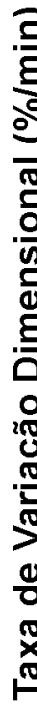

Figura 5: Taxa de variação dimensional de concretos com teores de cimento distintos.

[Figure 5: Dimensional change rate of castables with distinct amount of cement.] 


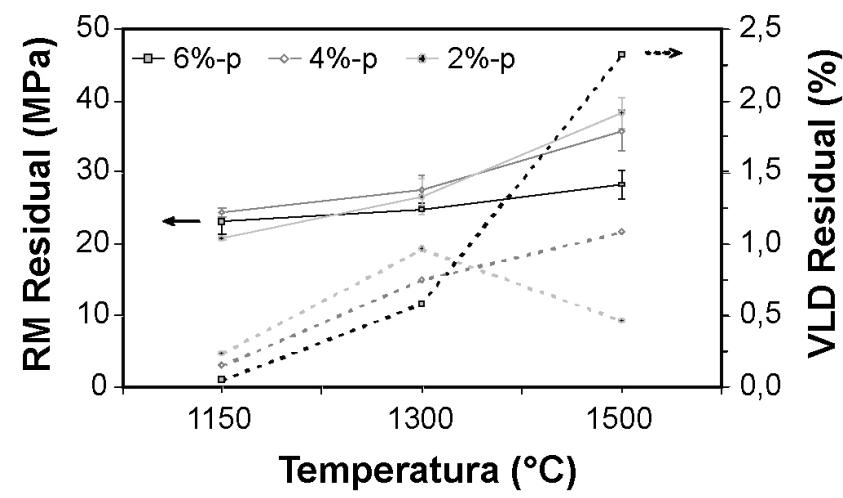

Figura 6: Resistência mecânica e VLD residual de concretos com teores de cimento distintos.

[Figure 6: Mechanical strength and permanent linear change of castables with distinct cement amount.]

relacionada à formação de $\mathrm{CA}_{6}$. Devido à expansão excessiva, a resistência mecânica do concreto com $6 \%$ $\mathrm{p}$ de cimento foi inferior à do concreto com baixo teor de cimento, ilustrado na Fig. 6.

Outro parâmetro que interfere na expansão é o tipo de magnésia adicionado. O tamanho de grão influencia no valor resultante de expansão, sendo que o aumento do tamanho de grão resulta em maior expansão, como mostra a Fig. 7. Evidentemente, esta expansão exagerada ocasiona um prejuízo na resistência mecânica do concreto, devido a um microtrincamento excessivo (Fig. 8). Tal resultado comprovou aqueles obtidos na literatura. [3].

Além do tamanho de grão, a pureza da magnésia também altera o comportamento do concreto com relação à expansão. Maiores purezas implicam em maiores teores de espinélio e, conseqüentemente, resultam em maior expansão. A Fig. 9 ilustra tal comportamento, indicando que o controle químico do tipo de magnésia utilizada pode auxiliar na obtenção da expansão resultante desejada. Novamente, a maior expansão

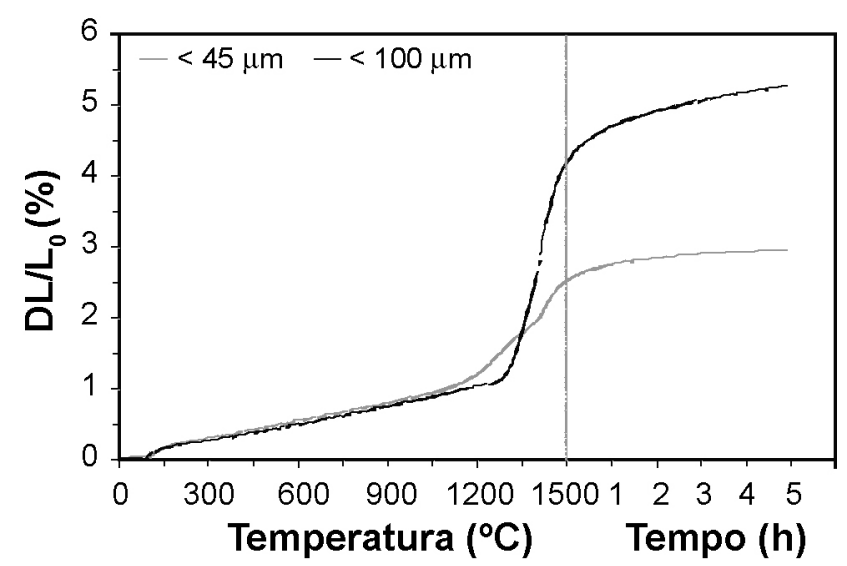

Figura 7: Expansão térmica de concretos contendo magnésias com tamanhos de grão distintos.

[Figure 7: Thermal expansion of castables with magnesia of distinct grain size.]

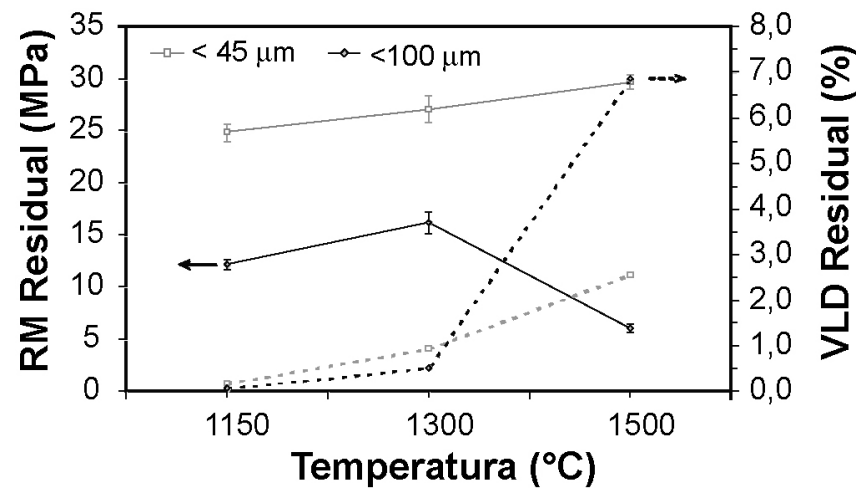

Figura 8: Resistência mecânica e VLD residual de concretos contendo magnésias com tamanhos de grão distintos.

[Figure 8: Mechanical strength and permanent linear change of castables with magnesia of distinct grain size.]

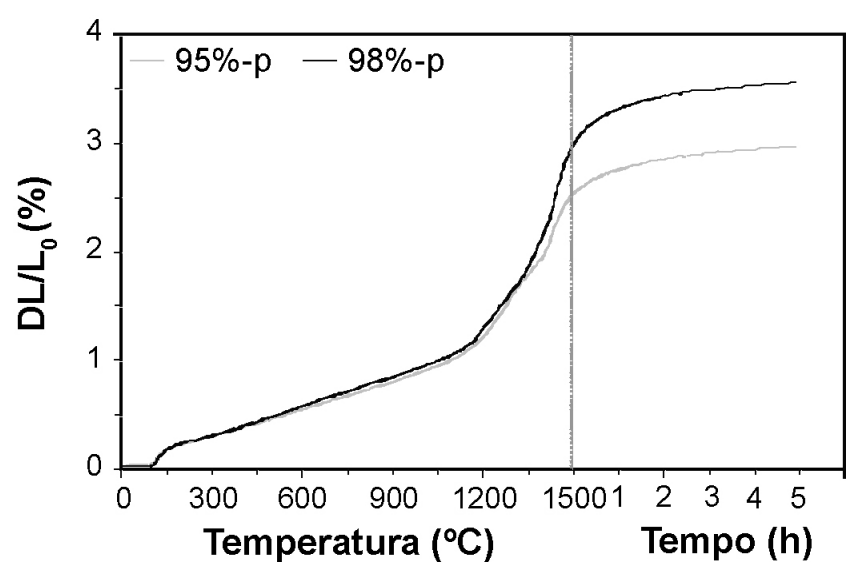

Figura 9: Expansão térmica de concretos contendo magnésias com purezas distintas.

[Figure 9: Thermal expansion of castables with magnesia of distinct purity.]

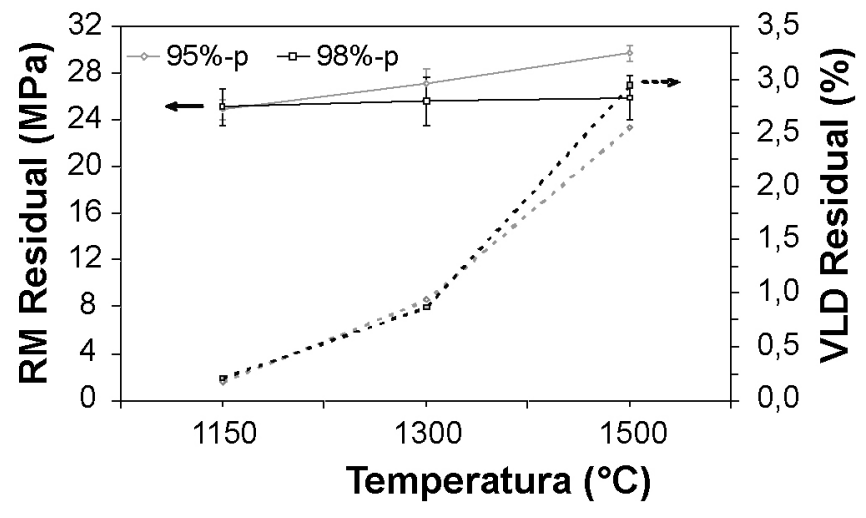

Figura 10: Resistência mecânica e VLD residual de concretos contendo magnésias com purezas distintas.

[Figure 10: Mechanical strength and permanent linear change of castables with magnesia of distinct purity.] 


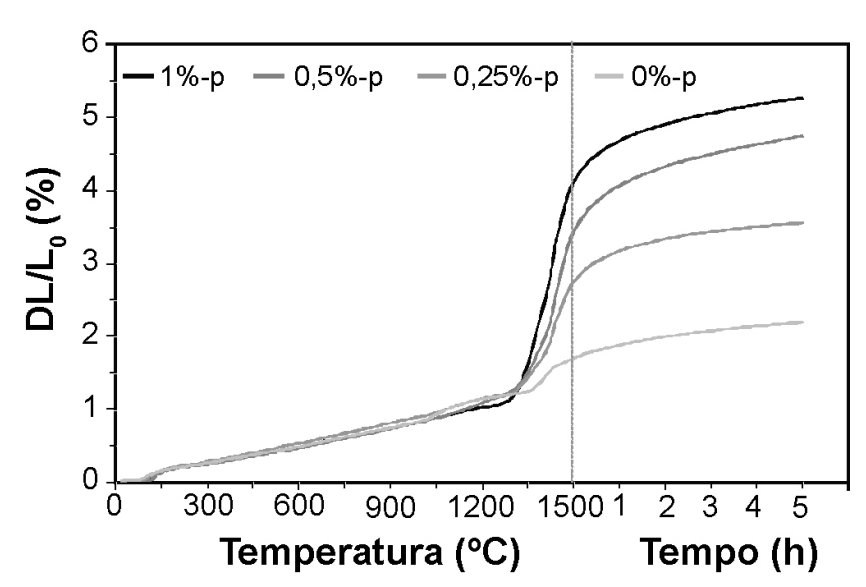

Figura 11: Expansão térmica de concretos contendo magnésia grosseira com teores de microssílica distintos.

[Figure 11: Thermal expansion of castables with the coarse magnesia and distinct fume silica content.]

gerada pelo sínter de maior pureza resulta em maior dano à resistência mecânica (Fig. 10).

Adicionalmente, a espinelização in-situ (e a expansão residual) é dependente da presença de microssílica. Esta matéria-prima age de forma particular nos diferentes tipos de concretos estudados. Por exemplo, no sínter mais grosseiro $(<100 \mu \mathrm{m})$ a retirada da microssílica possibilita a redução da expansão volumétrica final, como indica a Fig. 11. Sendo assim, a microssílica deve ser analisada de forma cautelosa, uma vez que interfere no resultado final de expansão e nas propriedades mecânicas a quente.

\section{CONCLUSÕES}

Os componentes da matriz de concretos alumina-magnésia interferem significativamente na expansão resultante da espinelização in-situ. Primeiramente, a presença de cimento de aluminato de cálcio contribui com a expansão resultante, devido à formação de $\mathrm{CA}_{6}$. Sendo assim, cuidados com o teor de cimento possibilitam o controle da expansão volumétrica.

Outra maneira de engenheirar a expansão é a avaliação do tipo de magnésia adicionada. Tanto o tamanho de grão quanto a pureza da magnésia influenciam na expansão do sistema, sendo a análise destes aspectos fundamental para se atingir as propriedades finais desejadas.

Adicionalmente, a microssílica é uma matéria-prima da matriz que altera de forma particular a expansão do sistema. No presente estudo, sua adição resultou em maior expansão volumétrica, indicando a possibilidade de alteração das propriedades do concreto por meio do controle do teor de microssílica.

Sendo assim, o conhecimento destes parâmetros e de seus efeitos nas propriedades do concreto é fundamental para a busca de uma expansão controlada que permita a tenacificação do sistema em ambientes constritos. Deste modo, materiais de elevados desempenhos podem ser obtidos, levando ao aumento de vida útil e maior produtividade de panelas para o refino secundário de aço.

\section{AGRADECIMENTOS}

À FAPESP, ao CNPq e à Magnesita S.A. pelo apoio para realização deste trabalho.

\section{REFERÊNCIAS}

[1] S. Mukhopadhyay, P. K. Das Poddar, Ceram. Int. 30 (2003) 369 .

[2] T. A. Bier, C. Parr, C. Revais, Proc. ALAFAR'97, San Juan, EUA (1997).

[3] K. Ide, T. Suzuki, K. Asano, T. Nishi, T. Isobe, H. Ichikawa, J. Techn. Assoc. Refract. 25 (2005) 202.

[4] J. Soudier, Proc. Unified Int. Conf. Refract., Orlando, EUA (2005).

[5] M. Fuhrer, A. Hey, W. E. Lee, J. Eur. Ceram. Soc. 18 (1998) 813.

[6] B. Myhre, B. Sandberg, A. M. Hundere, Proc. ALAFAR'97, San Juan, EUA (1997).

[7] H. Sarpoolaky, K. G. Ahari, W. E. Lee, Ceram. Int. 28 (2002) 487.

[8] S. K. Chen, M. Y. Cheng, S. J. Lin, Y. C. Ko, Ceram. Int. 28 (2002) 811.

[9] I. R. Oliveira, A. R. Studart, R. G. Pileggi, V. C. Pandolfelli, Dispersão e empacotamento de partículas - princípios e aplicações em processamento cerâmico, Fazendo Arte Editorial, S. Paulo, SP (2000) 119.

(Rec. 02/05/2007, Ac. 15/06/2007) 